\title{
Metabolic syndrome risk factors in overweight, obese, and extremely obese brazilian adolescents
}

\author{
Anapaula CB Rizzo ${ }^{1}$, Tamara BL Goldberg ${ }^{2 *}$, Carla C Silva ${ }^{3}$, Cilmery S Kurokawa ${ }^{4}$, Helio RC Nunes ${ }^{5}$ \\ and José E Corrente ${ }^{6}$
}

\begin{abstract}
Background: Obesity in infancy and adolescence has acquired epidemic dimensions worldwide and is considered a risk factor for a number of disorders that can manifest at an early age, such as Metabolic Syndrome (MS). In this study, we evaluated overweight, obese, and extremely obese adolescents for the presence of MS, and studied the prevalence of single factors of the syndrome in this population.
\end{abstract}

Methods: A total of 321 adolescents (174 females and 147 males) aged 10 to 16 years, attending the Adolescent Outpatient Clinic of Botucatu School of Medicine, Brazil, between April 2009 and April 2011 were enrolled in this study. Adolescents underwent anthropometric evaluation (weight, height, and abdominal circumference) and Body Mass Index (BMI) was estimated according to age and gender, following Disease Control and Prevention Centers recommendations (CDC, 2000). Blood pressure was measured and individuals with $\mathrm{BMI} \geq 85^{\text {th }}$ percentile were submitted to laboratory evaluation for Total Cholesterol, HDL and LDL Cholesterol, Triglycerides, Fasting Insulinemia, and Fasting Glycemia to identify MS factors, according to the criteria suggested by the International Diabetes Federation. Insulin resistance was calculated by HOMA-IR, Quicki, and Fasting Glycemia/Fasting Insulinemia (FGI).

Results and discussion: Of the 321 adolescents, 95 (29.6\%) were overweight, 129 (40.2\%) were obese, and 97 (30.2\%) were extremely obese. Around $18 \%$ were diagnosed with MS. The most prevalent risk factors were abdominal circumference $\geq 90^{\text {th }}$ percentile (55\%), $\mathrm{HDL}<40 \mathrm{mg} / \mathrm{dL}$ (35.5\%), High Pressure $\geq 130 / 85 \mathrm{~mm} / \mathrm{Hg}(21 \%)$, Triglycerides $\geq 150 \mathrm{mg} / \mathrm{dL}$ (18.5\%), and Fasting Glycemia $\geq 100 \mathrm{mg} / \mathrm{dL}$ (2\%). Insulin resistance was observed in 65\% of the adolescents.

Conclusion: An increased prevalence of overweight and obesity, together with cardiometabolic risk factors such as dyslipidemia and abnormal blood pressure, were observed in adolescents, contributing to the onset of metabolic syndrome at younger ages. Risk factors for MS were more prevalent in females.

Keywords: Obesity, Metabolic Syndrome, Adolescents, Risk factors, Insulin resistance

\section{Introduction}

Obesity in infancy and adolescence has acquired epidemic proportions worldwide, with a high prevalence in both developed and developing countries [1]. It is considered a risk factor for a number of serious disorders, such as Metabolic Syndrome (MS), which can manifest at early ages. MS consists of a group of metabolic abnormalities, and according to the International Diabetes Federation (IDF), characteristics of this syndrome include

\footnotetext{
* Correspondence: tamara@fmb.unesp.br

${ }^{2}$ Department of Pediatrics, Adolescent Medicine Course, Post Graduate Program in Gynecology, Obstetrics, and Mastology, Botucatu School of Medicine, São Paulo State University (UNESP), São Paulo, Brazil

Full list of author information is available at the end of the article
}

obesity, with emphasis on excess abdominal fat, hypertension, dyslipidemia, and hyperglycemia [2]. Insulin resistance seems to be the physiopathological basis for MS and hyperinsulinemia is considered a precursor for MS. Weight gain is an independent predictor for MS development although not seen in all obese individuals [2].

Recently, the potential consequences of obesity and metabolic syndrome in adolescents have gained greater attention. Studies have shown that the factors of MS, which are abnormal in infancy, often persist throughout adulthood [2-4]. The prevalence of MS among adolescents in the United States has increased over recent years, from $9.2 \%$ in the period from 1988 to 1994 , to

\section{Biomed Central}

(c) 2013 Rizzo et al.; licensee BioMed Central Ltd. This is an Open Access article distributed under the terms of the Creative Commons Attribution License (http://creativecommons.org/licenses/by/2.0), which permits unrestricted use, distribution, and reproduction in any medium, provided the original work is properly cited. 
$12.7 \%$ from 1999 to 2000 [5]. However, due to variations in the cutoff points adopted by different authors and a lack of consensus in defining the risk factors for MS, prevalence can vary according to the definition used and the population studied $[2,3,6]$.

The criteria for diagnosing MS in children and adolescents have been established by the IDF [2]. They are specific according to age ranges between 6 and 10 years, between 10 and 16 years, and 16 years and over. It has been suggested that Metabolic Syndrome should not be diagnosed in children under 10 years old, but a reduction in body weight should be encouraged in those with central obesity. Between 10 and 16 years, MS can be confirmed by central obesity, defined using the $90^{\text {th }}$ percentile values of waist circumference for gender and age, associated to other two factors (elevated triglycerides, low HDL cholesterol, arterial hypertension, and hyperglycemia). Diagnosis criteria for adolescents of 16 years or above are similar to those for adults.

This study aimed to evaluate overweight, obese, and extremely obese adolescents for the presence of MS, and to establish the prevalence of each factor of the syndrome in the population analyzed.

\section{Materials and methods}

Adolescents between 10 and 16 years old, of both genders, registered at the Adolescent Outpatient Clinic, Botucatu School of Medicine - UNESP, Brazil, between April 2009 and April 2011, were invited to participate in the study. Their parents or guardians signed an informed consent form. The study was approved by the Research Ethics Committee of Botucatu School of Medicine UNESP, protocol 357/08 CEP. The age group was chosen following the criteria proposed by the IDF [2].

Participants underwent clinical examination, including anthropometric [7] and nutritional evaluation. Nutritional status was evaluated using Body Mass Index (BMI) curves, weight $(\mathrm{kg}) /$ height $^{2}(\mathrm{~m})$, according to age and gender, and the respective cutoff points proposed by the Centers for Disease Control and Prevention, which are: eutrophic between the $5^{\text {th }}$ and $85^{\text {th }}$ percentiles; overweight or, according to CDC [8] guidelines, "at risk of overweight," greater than or equal to the $85^{\text {th }}$ percentile and less than the $95^{\text {th }}$ percentile; and obese, or according to CDC [8], "overweight," above the $95^{\text {th }}$ percentile [8]. In this study, we used the terms overweight and obese. Participants with gender- and age-adjusted BMI above the $99^{\text {th }}$ percentile were classified as extremely obese [9]. Abdominal circumference (AbdC) was measured at the midpoint between the iliac crest and the last rib [9-11]. These values were compared with the $90^{\text {th }}$ percentile values of waist circumference according to age and gender, using the curve proposed by Fernández et al. [10]. Blood (BP), Systolic (SBP), and Diastolic (DBP) pressure were measured.
Participants considered overweight, obese, or extremely obese by BMI calculation $(n=321)$ were submitted to laboratory exams for total cholesterol and fractions, triglycerides, basal insulinemia (also called fasting insulinemia), fasting glycemia, free Thyroxinemia (free T4), and thyroid stimulation hormone (TSH), to evaluate the presence of diagnostic criteria for MS or another disease. Values published by IDF for this specific age group are Triglycerides (TG) $\geq 150 \mathrm{mg} / \mathrm{dL}$, or specific treatment for this abnormality; HDL cholesterol (HDLc) $<40 \mathrm{mg} / \mathrm{dL}$ for both sexes, or specific treatment for this abnormality; arterial hypertension with $\mathrm{SBP} \geq 130 \mathrm{mmHg}$ or $\mathrm{DBP} \geq 85 \mathrm{mmHg}$ or specific treatment for arterial hypertension; and fasting glycemia $\geq 100 \mathrm{mg} / \mathrm{dL}$ or a previous diagnosis of type 2 diabetes [2].

Fasting glycemia and fasting insulinemia values were used to calculate HOMA-IR (Homeostasis model assessment of insulin resistance), Quicki (Quantitative insulin sensitivity check index), and FGI (fasting glucose to insulin ratio). The cutoff points used to identify insulin resistance in participants were: fasting insulinemia $>12 \mu \mathrm{U} / \mathrm{mL}$ [12]; HOMA-IR > 3.16 [13,14]; Quicki <0.313 [15]; and FGI $<7.0$ [15].

The exclusion criteria were as follows: presence of metabolic, endocrine, or genetic disease as reported in patient records, detected by general and special physical examination, or in laboratory or radiological procedures, as well as menstrual cycle changes that indicate the presence of Polycystic Ovary Syndrome (PCOS) in female participants.

\section{Statistical analysis}

Data for age, BMI, HDLc, TG, SBP and DBP, fasting Insulin and glycemia, HOMA-IR, Quicki, and FGI have asymmetric distribution. For comparison between gender-stratified groups, a generalized linear model (PROC GENMOD from SAS for Windows V9.2) with gamma distribution was used. Multiple comparisons were performed using the same program. AbdC data have symmetrical distribution and were analyzed using ANOVA followed by the Tukey test for gender-stratified groups. The level of significance adopted was $5 \%$.

Associations between MS criteria, nutritional state, and BMI data for gender-stratified groups were analyzed through the Chi-square test or exact Fisher test. In all tests, significance level was fixed at $5 \%$ or the corresponding $\mathrm{p}$ value was used.

\section{Results}

Out of 321 adolescents enrolled in this study, 95 (29.6\%) were classified as overweight by BMI, 129 (40.2\%) as obese, and $97(31.2 \%)$ as extremely obese. Of these, 174 (54.2\%) were female and 147 (45.8\%) were male. Table 1 shows nutritional and laboratory results, and the criteria for MS diagnosis for both female and male participants. 
Table 1 Nutritional assessment and laboratory variables for adolescents according to gender

\begin{tabular}{|c|c|c|c|c|c|c|}
\hline \multirow[t]{2}{*}{ FEMALE } & \multicolumn{2}{|c|}{ OVERWEIGHT $(n=55)$} & \multicolumn{2}{|c|}{ OBESE $(n=71)$} & \multicolumn{2}{|c|}{ EXTREMELY OBESE $(n=48)$} \\
\hline & $x$ & SD & $x$ & SD & $x$ & SD \\
\hline Age (years) ${ }^{(1) ~ N S}$ & $13.28^{\mathrm{a}}$ & 2.26 & $12.66^{\mathbf{a b}}$ & 2.05 & $12.45^{\mathbf{b}}$ & 1.61 \\
\hline BMI $\left(\mathbf{k g} / \mathbf{m}^{2}\right)^{(1)^{* *}}$ & $25.10^{\mathbf{a}}$ & 2.62 & $27.98^{\mathbf{b}}$ & 3.07 & $33.99^{c}$ & 5.17 \\
\hline $\operatorname{AbdC}(\mathrm{cm})^{(2)^{* *}}$ & $82.84^{\mathrm{a}}$ & 8.34 & $87.39^{\mathbf{b}}$ & 8.85 & $95.84^{c}$ & 10.68 \\
\hline HDLc $(m g / d L)^{(1)^{* *}}$ & $49.24^{a}$ & 9.95 & $42.19^{\mathbf{b}}$ & 8.68 & $40.53^{c}$ & 13.08 \\
\hline $\mathrm{TG}(\mathbf{m g} / \mathbf{d L})^{(1)^{* *}}$ & $92.11^{\mathrm{a}}$ & 35.74 & $107.41^{\mathbf{b}}$ & 68.11 & $121.33^{\mathbf{b c}}$ & 46.38 \\
\hline $\mathrm{SBP}^{(1)^{* *}}$ & $110.73^{\mathbf{a}}$ & 8.18 & $116.24^{\mathbf{b}}$ & 14.53 & $127.58^{c}$ & 18.40 \\
\hline $\mathrm{DBP}^{(1)^{* *}}$ & $68.66^{a}$ & 6.89 & $71.47^{\mathrm{ab}}$ & 12.63 & $81.93^{c}$ & 12.12 \\
\hline Glycemia (mg/dL) ${ }^{(1) N S}$ & $82.60^{\mathrm{a}}$ & 8.43 & $83.58^{\mathrm{a}}$ & 15.85 & $82.56^{\mathrm{a}}$ & 7.52 \\
\hline Insulin $(\mu \mathbf{U} / \mathbf{m L})^{(1)^{* *}}$ & $13.78^{\mathbf{a}}$ & 4.79 & $17.58^{\mathbf{b}}$ & 10.22 & $20.38^{\mathbf{b c}}$ & 9.50 \\
\hline HOMA-IR $\mathbf{R}^{(1)^{* *}}$ & $2.79^{a}$ & 0.99 & $3.65^{\mathbf{b}}$ & 2.26 & $4.12^{\mathbf{b c}}$ & 1.84 \\
\hline Quicki $^{(1)^{* *}}$ & $0.33^{\mathrm{a}}$ & 0.02 & $0.32^{\mathbf{b}}$ & 0.02 & $0.32^{\mathbf{b c}}$ & 0.02 \\
\hline $\mathrm{FGI}^{(1)^{* *}}$ & $7.37^{\mathbf{a}}$ & 7.03 & $5.88^{\mathbf{b}}$ & 2.69 & $5.12^{\mathbf{b c}}$ & 3.18 \\
\hline \multirow[t]{2}{*}{ MALE } & \multicolumn{2}{|l|}{$(n=40)$} & \multicolumn{2}{|l|}{$(n=58)$} & \multicolumn{2}{|l|}{$(n=49)$} \\
\hline & $x$ & SD & $x$ & SD & $x$ & SD \\
\hline Age (years) ${ }^{(1) N S}$ & $12.62^{a}$ & 1.76 & $12.89^{\mathrm{a}}$ & 1.68 & $12.65^{\mathrm{a}}$ & 2.22 \\
\hline BMI $\left(\mathbf{k g} / \mathbf{m}^{2}\right)^{(1)^{* *}}$ & $24.07^{\mathrm{a}}$ & 2.12 & $27.12^{\mathbf{b}}$ & 2.69 & $32.13^{c}$ & 4.11 \\
\hline $\operatorname{AbdC}(\mathrm{cm})^{(2)^{* *}}$ & $81.03^{\mathrm{a}}$ & 7.54 & $86.02^{\mathrm{ab}}$ & 10.14 & $95.19^{c}$ & 11.28 \\
\hline HDLc (mg/dL) ${ }^{(1) N S}$ & $43.10^{a}$ & 8.31 & $44.22^{a}$ & 11.37 & $44.31^{a}$ & 8.97 \\
\hline $\mathrm{TG}(\mathrm{mg} / \mathrm{dL}){ }^{(1) \mathrm{NS}}$ & $103.38^{\mathrm{a}}$ & 76.60 & $95.71^{\mathrm{ab}}$ & 58.68 & $117.83^{\mathrm{ac}}$ & 55.34 \\
\hline $\mathrm{SBP}^{(1)^{* *}}$ & $111.17^{\mathbf{a}}$ & 15.01 & $115.16^{\mathbf{a b}}$ & 14.10 & $125.98^{c}$ & 13.06 \\
\hline $\mathrm{DBP}^{(1)^{* *}}$ & $69.28^{a}$ & 10.70 & $74.73^{\mathbf{b c}}$ & 10.20 & $76.88^{c}$ & 12.17 \\
\hline Glycemia (mg/dL) ${ }^{(1) N S}$ & $83.59^{\mathrm{a}}$ & 7.22 & $83.77^{\mathrm{a}}$ & 7.90 & $86.51^{\mathrm{a}}$ & 5.79 \\
\hline Insulin $(\mu \mathbf{U} / \mathbf{m L})^{(1) N S}$ & $13.72^{\mathbf{a}}$ & 9.90 & $14.08^{\mathrm{a}}$ & 7.64 & $16.13^{\mathrm{a}}$ & 8.07 \\
\hline HOMA-IR ${ }^{(1) N S}$ & $2.84^{\mathrm{a}}$ & 2.03 & $2.89^{a}$ & 1.62 & $3.45^{\mathrm{a}}$ & 1.71 \\
\hline Quicki $^{(1)^{* *}}$ & $0.34^{a}$ & 0.04 & $0.33^{\mathrm{ab}}$ & 0.03 & $0.32^{\mathbf{b}}$ & 0.02 \\
\hline $\mathbf{F G I}^{(1)^{* *}}$ & $10.86^{\mathbf{a}}$ & 10.43 & $7.84^{\mathbf{b}}$ & 5.99 & $6.32^{\mathbf{b c}}$ & 2.38 \\
\hline
\end{tabular}

Note: (1) Multiple comparison using PROC GENMOD from SAS program.

(2) Multiple comparisons using ANOVA and Tukey test.

${ }^{*} p<0.05 * * 0<0.01$ NS not significant.

The same letters show no statistically significant difference.

Total number of female adolescents $=\mathbf{1 7 4}$.

Total number of male adolescents $=\mathbf{1 4 7}$.

BMI Body Mass Index, AbdC Abdominal circumference, HDLc-HDL cholesterol, TGTriglycerides, SBP Systolic Blood Pressure, DBP Diastolic Blood Pressure, HOMA-IR Homeostasis model assessment of insulin resistance Quicki Quantitative insulin sensitivity check index, FGI Fasting glucose to insulin ratio.

Regarding age, no significant differences were observed in comparisons between overweight, obese, and extremely obese groups for both male and female participants (Table 1).

Anthropometric values and MS criteria increased in direct proportion from the overweight to extremely obese female adolescent groups. Differences were statistically significant with the exception of glycemia (Table 1). The highest HDLc values were found in the overweight girl group, and the lowest values in the extremely obese girl group $(\mathrm{p}<0.0001)$.

Mean fasting insulinemia values significantly increased from the overweight to the extremely obese girl group $(\mathrm{p}<0.0001)$. The same was observed for HOMA-IR, where values increased in direct proportion from the overweight to extremely obese girl groups $(\mathrm{p}<0.0001)$. The inverse was observed for Quicki and FGI mean values.

For male adolescents, the variables considered as risk factors for MS increased in direct proportion from the overweight to the extremely obese groups. However, no significant differences were observed for triglycerides, glycemia, and HDLc values between groups analyzed, and for fasting insulin and HOMA-IR. Mean Quicki and FGI values decreased in direct proportion from the overweight to extremely obese groups $(\mathrm{p}=0.0031$ and $\mathrm{p}<0.0001)$. 
Table 2 shows the prevalence of MS factors, according to IDF criteria, in all overweight, obese, and extremely obese adolescent groups classified by BMI and stratified by gender. Altered abdominal circumference was the most prevalent factor (55\%), followed by reduced HDLc levels (35\%), elevated pressure (21\%), and elevated TG levels (18.5\%). According to BMI classification, AbdC was the most prevalent criteria occurring in $87 \%$ of adolescents considered extremely obese.

In females, the most prevalent criterion was altered AbdC, which varied from $41.9 \%$ in the overweight group to $96.6 \%$ in the extremely obese group ( $\mathrm{p}<0.001$ ), followed by decreased HDLc levels, varying from $22.6 \%$ in the overweight group to $51.7 \%$ in the extremely obese group $(p=0.040)$. Arterial hypertension was the third most common factor of MS, occurring in $9.7 \%$ of overweight and in $41.4 \%$ of extremely obese girls ( $p=0.007$ ).

In males, the most frequent MS factor was abnormal abdominal circumference, which varied from $21.1 \%$ in the overweight group to $76.0 \%$ in the extremely obese group ( $\mathrm{p}<0.001)$. Decreased HDLc was the second most prevalent, but with no significant difference between groups, this was followed by hypertension and high triglyceride levels. The prevalence of hypertension was significantly higher in extremely obese than in overweight boys $(\mathrm{p}=0.057)$ (Table 2$)$. For both genders, altered glycemia was the least prevalent MS factor in all groups (Table 2).

When MS was diagnosed following IDF criteria, considering the presence of at least three out of five metabolic abnormalities, we found that from the 321 adolescents evaluated, 59 (18.3\%) were positive for MS, of whom 32 were female and 27 were male. By the Exact Fisher test, the highest MS percentages were observed in the extremely obese groups regardless of gender $(41.7 \%$ females and $30.6 \%$ males), and differed significantly to the other groups $(\mathrm{p}<0.001$ for females and $\mathrm{p}<0.0042$ for males).

From the 321 adolescents evaluated, 65\% presented insulin resistance. Of the different methods used to evaluate insulin resistance, fasting insulinemia and fasting glucose to insulin ratio (FGI) resulted in the highest percentages of insulin-resistant adolescents (Table 3).

\section{Discussion}

The prevalence of metabolic syndrome in obese children and adolescents has increased worldwide. Obese children have higher abdominal fat, which is associated with hyperinsulinism and cardiometabolic alterations such as low HDLc, increased triglycerides and LDLc, and increased blood pressure, resulting in increased risk for type 2 diabetes and cardiovascular diseases [6,9,16-19].

Table 2 Prevalence of Metabolic Syndrome factors in all overweight, obese, and extremely obese adolescents according to BMI and by gender

\begin{tabular}{|c|c|c|c|c|c|}
\hline & & General $(n=321)$ & Overweight $(n=95)$ & Obese $(n=129)$ & Extremely obese $(n=97)$ \\
\hline \multirow[t]{6}{*}{ Total } & $\mathrm{AbdC}>90^{\text {th }} \mathrm{P}(1)^{* *}$ & $55.0 \%$ & $30.4 \%^{a}$ & $54.5 \%$ b & $87.0 \%{ }^{c}$ \\
\hline & $\mathrm{TG} \geq 150 \mathrm{mg} / \mathrm{dL}^{(1)^{*}}$ & $18.5 \%$ & $15.9 \%{ }^{\text {ab }}$ & $13.0 \%^{a}$ & $29.6 \% \mathbf{b}$ \\
\hline & $\mathrm{HDLc}<40 \mathrm{mg} / \mathrm{dL}^{(1) \mathrm{NS}}$ & $35.5 \%$ & $29.0 \%^{a}$ & $37.7 \%{ }^{\mathbf{a}}$ & $40.7 \%^{\mathbf{a}}$ \\
\hline & SBP-DBP $\geq 130 / 85^{(1)^{* *}}$ & $21.0 \%$ & $10.1 \%^{\mathbf{a}}$ & $18.2 \%^{\text {a }}$ & $38.9 \% \mathbf{b}$ \\
\hline & Glycemia $\geq 100 \mathrm{mg} / \mathrm{dL}^{(2) \mathrm{Ns}}$ & $2.0 \%$ & $2.9 \%^{\mathbf{a}}$ & $1.3 \%{ }^{\mathbf{a}}$ & $1.9 \%^{\mathbf{a}}$ \\
\hline & & $(n=174)$ & $(n=55)$ & $(n=71)$ & $(n=48)$ \\
\hline \multirow[t]{6}{*}{ Female } & $\mathrm{AbdC}>90^{\text {th }} \mathrm{P}(2)^{* *}$ & $67.0 \%$ & $41.9 \%^{a}$ & $65.0 \%{ }^{a}$ & $96.6 \% \mathbf{b}$ \\
\hline & $\mathrm{TG} \geq 150 \mathrm{mg} / \mathrm{dL}^{(2) \mathrm{NS}}$ & $19.0 \%$ & $12.9 \%^{\mathbf{a}}$ & $15.0 \%^{\mathrm{a}}$ & $31.0 \%^{a}$ \\
\hline & $\mathrm{HDLc}<40 \mathrm{mg} / \mathrm{dL}^{(1)^{*}}$ & $41.0 \%$ & $22.6 \%^{a}$ & $47.5 \%{ }^{a b}$ & $51.7 \% \mathbf{b}$ \\
\hline & SBP-DBP $\geq 130 / 85^{(2)^{* *}}$ & $21.0 \%$ & $9.7 \%^{\mathbf{a}}$ & $15.0 \%^{\mathrm{a}}$ & $41.4 \%^{\mathbf{b}}$ \\
\hline & Glycemia $\geq 100$ mg/dL ${ }^{(2) N s}$ & $3.0 \%$ & $3.2 \%{ }^{\mathbf{a}}$ & $2.5 \%{ }^{\mathbf{a}}$ & $3.4 \%{ }^{\mathrm{a}}$ \\
\hline & & $(n=147)$ & $(n=40)$ & $(n=58)$ & $(n=49)$ \\
\hline \multirow[t]{5}{*}{ Male } & $A b d C>90^{\text {th }} P^{(1)^{* *}}$ & $43.0 \%$ & $21.1 \%^{a}$ & $43.2 \%^{a}$ & $76.0 \%{ }^{\mathbf{b}}$ \\
\hline & $\mathrm{TG} \geq 150 \mathrm{mg} / \mathrm{dL}^{(2) \mathrm{NS}}$ & $18.0 \%$ & $18.4 \%^{a}$ & $10.8 \%^{\mathbf{a}}$ & $28.0 \%^{a}$ \\
\hline & $\mathrm{HDLc}<40 \mathrm{mg} / \mathrm{dL}^{(1) \mathrm{NS}}$ & $30.0 \%$ & $34.2 \%{ }^{a}$ & $27.0 \%^{\mathrm{a}}$ & $28.0 \%^{a}$ \\
\hline & SBP-DBP $\geq 130 / 85^{(2)^{*}}$ & $21.0 \%$ & $10.5 \%^{\mathbf{a}}$ & $21.6 \%{ }^{a b}$ & $36.0 \%$ b \\
\hline & Glycemia $\geq 100 \mathrm{mg} / \mathrm{dL}^{(2) \mathrm{Ns}}$ & $1.0 \%$ & $2.6 \%{ }^{a}$ & $0.0 \%{ }^{a}$ & $0.0 \%{ }^{\mathbf{a}}$ \\
\hline
\end{tabular}


Table 3 Percentage of insulin-resistant adolescents according to method

\begin{tabular}{llll}
\hline Method and reference value & $\begin{array}{l}\text { General } \\
(\mathbf{n}=\mathbf{3 2 1})\end{array}$ & $\begin{array}{l}\text { Females } \\
(\mathbf{n}=\mathbf{1 7 4})\end{array}$ & $\begin{array}{l}\text { Males } \\
(\mathbf{n}=\mathbf{1 4 7})\end{array}$ \\
\hline Insulin $\geq 12 \mu \mathrm{U} / \mathrm{mL}$ & $64.0 \%$ & $74.0 \%$ & $54.0 \%$ \\
HOMA $>3.16$ & $43.5 \%$ & $54.0 \%$ & $33.0 \%$ \\
Quicki $<0.313$ & $25.0 \%$ & $32.0 \%$ & $18.0 \%$ \\
FGI $<7.0$ & $65.0 \%$ & $75.0 \%$ & $55.0 \%$ \\
\hline
\end{tabular}

Our results are from a transversal study performed at initial clinical and nutritional evaluation of adolescents when they spontaneously signed up for consultation at the Adolescent Medicine Outpatient Clinic, which sees adolescents between 10 and 20 years of age and where consultations are arranged in advance [where the only limiting factor is the availability of professionals in this area to provide consultations]. In the study period, 321 adolescents between 10 and 16 years of age who presented with excess weight were included in the sample. We stress again that the participants are from a sample constructed for convenience, however those making up the sample were sequentially introduced, a measure incorporated into the treatment provided at the outpatient clinic. Therefore our results should be used with caution in overweight, obese, and extremely obese adolescents from other populations.

We found a high prevalence of overweight, obese, and extremely obese adolescents, together with a high prevalence of cardiometabolic risk factors, such as dyslipidemia and blood pressure alterations, in these individuals, potentially contributing to MS onset at early ages. The high prevalence of obesity found in this study clearly reflects the process of nutritional transition occurring in Brazil, through which undernutrition is replaced by obesity [20,21]. In a retrospective study of adolescents who also attended this clinic between 1988 and 1996, the authors showed that overweight and obesity doubled in females and more than tripled in males during this period [22]. Another study reported that the percentage of individuals who presented MS factors almost doubled over a ten-year period [19]

Anthropometric measurements, especially abdominal circumference, are crucial for MS diagnosis. In addition, measurements of serum lipid fractions, fasting glucose values, and blood pressure in susceptible or overweight individuals are also important. Evaluation of fasting insulin has been highlighted, given that a strong association between basal hyperinsulinemia, blood pressure alterations, and dyslipidemia has been demonstrated. Furthermore, insulin resistance has been indicated as the physiological basis for MS [23,24], since it precedes diabetes, anticipating insulin secretion failure [25]. It has also been suggested that hyperinsulinemia precedes the appearance of MS in infancy and adolescence, possibly explaining the association between obesity and the observed vascular dysfunctions [18].

In this study, an abnormal abdominal circumference was the most prevalent anthropometric parameter for both male and female adolescents, being more frequent in extremely obese females (96.6\%) than in extremely obese males (76\%). Of the 321 adolescents analyzed, 31\% had at least one cardiometabolic risk factor, $26 \%$ had at least two, and $25 \%$ did not present any of the risk factors. The prevalence of three or more risk factors was higher in the extremely obese groups of both genders, at $41.7 \%$ in females and $30.6 \%$ in males. A previous study performed in Bogalusa, USA, found that $26 \%$ of adolescents had at least one risk factor and $4 \%$ had at least three risk factors. In extremely obese adolescents, 34\% of females and $32 \%$ of males had at least three risk factors [9].

We also observed that the metabolic abnormalities were more significant and frequent in individuals with higher BMI values, specifically in obese and extremely obese adolescents compared to those considered overweight. Altered HDLc was the most frequent of the cardiometabolic parameters, followed by abnormal blood pressure and triglycerides levels. When the metabolic abnormalities were analyzed in groups stratified by gender, we observed an increased prevalence in females. Approximately $50 \%$ of extremely obese females had low HDLc levels and 30\% had increased triglycerides. In males, HDLc was the most frequent (30\%) altered cardiometabolic parameter, followed by increased blood pressure $(21 \%)$, the latter being the most prevalent abnormality found in extremely obese males, with a frequency of $36 \%$.

When analyzing the variables associated with insulin resistance, we found significant differences in adolescent female groups for all criteria. A higher percentage of girls $(75 \%)$, than boys (55\%), presented insulin resistance according to FGI values. Moran et al. [26]; Barja et al. [27]; Jeffery et al. [28] support our findings, as they stress the influence of sexual dimorphism, which results from the earlier appearance of secondary sexual characteristics in girls compared to boys, external biological expression modulated by hormonal ebullience belonging to the puberty years. For Jeffery et al., HOMA-IR levels were higher in girls than boys at all evaluated ages, from 7 to 14 years, even after adjustments, presenting their peak when the adolescents were found in Tanner stage 3 and 4, moments associated with peak height velocity [28]. Regardless of gender, the extremely obese group presented the highest degree of insulin resistance. Our data differ from a previous study in which no significant differences in fasting insulin values were observed among eutrophic, overweight, and obese groups [4], possibly because analyses were conducted according to 
gender. We would like to emphasize that the cutoff points used in this study for anthropometric and biochemical variables and for insulin resistance are those recommended by IDF [2] for the studied age band, found in related international scientific literature [1315], stressing that specific values for the Brazilian adolescent population are still not available. We believe that these values will soon be available as a large population study called the ERICA study (Study of Cardiovascular Risks in Adolescents) is being developed.

Considering the IDF criteria for MS diagnosis [2], we showed that around $18 \%$ of the adolescents analyzed presented the syndrome, which was more prevalent in extremely obese individuals, especially females.

A study in India with 2640 adolescents of both genders produced similar results; in eutrophic and overweight/obese adolescents, abnormalities in triglycerides, HDLc, basal insulin, and insulin resistance levels evaluated by HOMA-IR were higher in females. HOMA-IR values were much higher in individuals presenting parameters indicative of MS. Altered cardiometabolic parameters, of which reduced HDLc and increased triglycerides were the most common, were more frequent in overweight adolescents. Increased abdominal circumference was found in approximately $86 \%$ of overweight/obese adolescents [11].

The transversal approach used in this study raises the question of instability in metabolic syndrome diagnosis. Considering the intense growth and puberty changes, a longitudinal follow-up of our study individuals would be necessary. Nevertheless, studies have shown that $85 \%$ of obese individuals in this age group remain obese in adulthood [4,9] and many are diagnosed with MS. Even though some of these patients do not present the syndrome in the following years, its diagnosis during childhood and adolescence reinforces the importance of implementing effective treatment at an early age. Preventive measures aimed at reducing the incidence of obesity and its consequences at younger ages should also be adopted.

\section{Competing interests}

The authors declare that they have no competing interest.

\section{Authors' contribution}

ACBR performed the sample collection, nutritional assessments, processed the data and drafted the manuscript. TBLG designed the study, performed the sample collection, nutritional assessments and processed the data, analyzed data and drafted the manuscript. CCS and CSK helped in data interpretation and in drafting of the manuscript. HRCN and JEC conducted statistical analysis and drafted the manuscript. All authors have read and approved the final version.

\section{Acknowledgements}

This manuscript has been reviewed by a professional science editor and a native English-speaking copy editor to improve readability.

Supported by FAPESP (Fundação de Amparo à Pesquisa do Estado de São Paulo) - Process no. 2011/05991-0.

\section{Author details}

'Department of Pediatrics, Botucatu School of Medicine, São Paulo State University (UNESP), São Paulo, Brazil. ${ }^{2}$ Department of Pediatrics, Adolescent Medicine Course, Post Graduate Program in Gynecology, Obstetrics, and Mastology, Botucatu School of Medicine, São Paulo State University (UNESP), São Paulo, Brazil. ${ }^{3}$ Department of Physical Education, University of North Paraná, Paraná, Brazil. ${ }^{4}$ Clinical and Experimental Pediatric Research Center, Department of Pediatrics, Botucatu School of Medicine, São Paulo State University (UNESP), São Paulo, Brazil. ${ }^{5}$ Statistical Consultant, Botucatu School of Medicine, São Paulo State University (UNESP), São Paulo, Brazil.

${ }^{6}$ Department of Statistics, Botucatu School of Medicine, São Paulo State

University (UNESP), São Paulo, Brazil.

Received: 5 September 2012 Accepted: 23 January 2013

Published: 30 January 2013

\section{References}

1. Ogden CL, Carroll MD, Kit BK, Kit BK, Flegal KM: Prevalence of obesity and trends in body mass index among US children and adolescents, 1999-2010. JAMA 2012, 307:483-490. http://dx.doi.org/10.1001/jama.2012.40.

2. Zimmet P, Alberti KGMM, Kaufman F, Tajima N, Silink M, Arslanian S, Wong G, Bennett P, Shaw J, Caprio S, IDF Consensus Group: The metabolic syndrome in children and adolescents - an IDF consensus report. Pediatr Diabetes 2007, 8:299-306. doi:10.1111/j.1399-5448.2007.00271.x.

3. Cook S, Weitzman M, Auinger $P$, Nguyen M, Dietz WH: Prevalence of a metabolic syndrome phenotype in adolescents: findings from the Third National Health and Nutrition Examination Survey, 1988-1994. Arch Pediatr Adolesc Med 2003, 157:821-827. doi:10.1001/ archpedi.157.8.821.

4. Goodman E, Daniels SR, Meigs IB, Dolan LM: Instability in the diagnosis of Metabolic Syndrome in adolescents. Circulation 2007, 115:2316-2322. doi:10.1161/CIRCULATIONAHA.106.669994.

5. de Ferranti SD, Gauvreau K, Ludwig DS, Newburger JW, Rifai N: Inflammation and changes in metabolic syndrome abnormalities in US adolescents: findings from the 1988-1994 and 1999-2000 National Health and Nutrition Examination Surveys. Clin Chem 2006, 52:1325-1330. doi:10.1373/clinchem.2006.067181.

6. Courtney J, Jolliffe CJ, Janssen I: Development of age-specific adolescent metabolic syndrome criteria that are linked to the Adult Treatment Panel III and international Diabetes Federation criteria. J Am Coll Cardiol 2007, 49:891-898. doi:10.1016/j.jacc.2006.08.065.

7. Gordon CC, Chumled WC, Roche AF: Stature, recumbent length and weight. In Anthropometric standardization reference manual. Edited by Lohman TG, Roche AF, Martorell R. Champaign IL: Human Kinetics Books; 1988:177.

8. Center for Disease Control and Prevention: The 2000 CDC Growth Charts and the New Body Mass Index-For-Age Charts. CDC Growth Charts: United States. Available from. http://www.cdc.gov/nchs/about/major/nhanes/ growthcharts/charts.htm.

9. Freedman D, Mei Z, Srinivasan S, Berenson G, Dietz W: Cardiovascular Risk Factors and Excess Adiposity Among Overweight Children and Adolescents: The Bogalusa Heart Study. J Pediatr 2007, 150:12-17. doi:10.1016/j.jpeds.2006.08.042.

10. Fernández J, Redden D, Pietrobelli A, Allison D: Waist Circumference Percentiles in nationally representative samples of African-American, European-American, and Mexican-American children and adolescents. J Pediatr 2004, 145:439-444. doi:10.1016/j.jpeds.2004.06.044

11. Ramachandran A, Snehalatha C, Yamuna A, Murugesan N, Narayan V: Insulin resistence and clustering of cardiometabolic risk factors in urban teenagers in Southern India. Diabetes Care 2007, 30:1828-1833. doi:10.2337/dc06-2097.

12. Carmina E, Napoli N, Longo RA, Rini GB, Lobo RA: Use of fasting blood to assess the prevalence of Insulin Resistance in women with Polycystic Ovary Syndrome. Fertil Steril 2004, 82:661-665. doi:10.1530/eje.1.02058.

13. Tresaco B, Bueno G, Pineda I, Moreno LA, Garagorri JM, Bueno M: Homeostatic model assessment (HOMA) index cut-off values to identify the metabolic syndrome in children. J Physiol Biochem 2005, 61:381-388.

14. Dimartino-Nardi J: Premature adrenarche: findings in prepubertal AfricanAmerican and Caribbean-Hispanic girls. Acta Paediatr Supp 1999, 88:67-72. doi:10.1111/j.1651-2227.1999.tb14406.x. 
15. Keskin $M$, Kurtoglu $S$, Kendirci $M$, et al: Homeostasis model assessment is more reliable than the fasting glucose/insulin ratio and quantitative insulin sensitivity check index for assessing insulin resistance among obese children and adolescents. Pediatr; 2005, 115:e500-e503. doi:10.1542/ peds.2004-1921.

16. Sinaiko AR, Steinberger J, Moran A, Hong C-P, Prineas RJ, Jacobs DR Jr: Influence of insulin resistance and body mass index at age 13 on systolic blood pressure, triglycerides, and high-density lipoprotein cholesterol at age 19. Hypertension 2006, 48:730-736. doi:10.1161/01. HYP.0000237863.24000.50.

17. Goran MI, Gower BA: Longitudinal study on pubertal insulin resistance. Diabetes 2001, 50:2444-2450. doi:10.2337/diabetes.50.11.2444.

18. Aggoun Y: Obesity, Metabolic Syndrome, and Cardiovascular Disease. Pediatr Res 2007, 61:653-659. doi:10.1203/pdr.0b013e31805d8a8c.

19. Franco OH, Massaro JM, Civil J, Cobain MR, O'Malley B, Agostino R: Trajectories of entering the Metabolic Syndrome: The Framingham Heart Study. Circulation 2009, 120:1943-1950. doi:10.1161/ CIRCULATIONAHA.109.855817.

20. Instituto Brasileiro de Geografia e Estatística - IBGE: Análise da disponibilidade domiciliar de alimentos e do estado nutricional no Brasil. 2005. Available from. http://www.ibge.com.br.

21. Instituto Brasileiro de Geografia e Estatística: Pesquisa de orçamentos familiares - POF 2002-2003. Análise do estado nutricional no Brasil. 2006. Available from. http://www.ibge.com.br.

22. Goldberg TBL, Baiocchi Neto G, Garcia DA, Curi PR: Experiências em pesquisas: comparação entre indicadores nutricionais para o diagnóstico de sobrepeso e obesidade entre adolescentes. In Obesidade e Anemia Carencial na Adolescência. São Paulo: Instituto Danone; 2000:255-5.

23. Reilly JJ, Methven E, McDowell ZC, Hacking B, Alexander D, Stewart L, Kelnar CJ: Health consequences of obesity. Arch Dis Child 2007, 88:748-752. doi:10.1136/adc.88.9.748

24. Lottenberg S, Glezer A, Turatti L: Metabolic syndrome: identifying the risk factors. J Pediatr 2007, 83:S204-S208. doi:10.2223/JPED.1715.

25. Weyer C, Bogardus C, Mott DM, Pratley RE: The natural history of insulin secretory dysfunction and insulin resistance in the pathogenesis of type 2 diabetes mellitus. J Clin Invest 1999, 104:787-794. doi:10.1172/JCI7231.

26. Moran A, Jacobs DJ, Steinberger J Jr, Steffen LM, Pankow JS, Hong CP, Sinaiko AR: Changes in Insulin Resistance and Cardiovascular Risk During Adolescence: Establishment of Differential Risk in Males and Females. Circulation 2008, 117:2361-2368. doi:10.1161/CIRCULATIONAHA.107.704569.

27. Barja S, Arnaiz P, Dominguez A, Villarroel L, Cassis B, Castillo O, Salomó G, Farias M, Goycoolea M, Quiroga T, Mardones F: Insulinemia e índice HOMA en niños y adolescentes chilenos. Rev Med Chile 2011, 139:1435-1443.

28. Jeffery AN, Metcalf BS, Hosking J, Streeter AJ, Voss LD, Wilkin TJ: Age Before Stage: Insulin Resistance Rises Before the Onset of Puberty. A 9-year longitudinal study (EarlyBird 26). Diabetes Care 2012, 35(3):536-541. doi:10.2337/dc11-1281

\section{Submit your next manuscript to BioMed Central and take full advantage of:}

- Convenient online submission

- Thorough peer review

- No space constraints or color figure charges

- Immediate publication on acceptance

- Inclusion in PubMed, CAS, Scopus and Google Scholar

- Research which is freely available for redistribution 